\title{
Relationship between Molar Root Trunk Type and Molar Loss in Individuals with Class III Furcation Involvements: A Retrospective Study
}

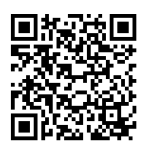

\author{
Guey Lin Hou ${ }^{1,2 *}$ \\ ${ }^{1}$ Department of Periodontal Prosthesis, Kaohsiung Medical University, Taiwan
}

${ }^{2}$ Department of Periodontal \& Prosthetic Therapeutic Center \& Periodontal, Chang Gung Memorial Hospital, Kaohsiung Medical Center, Taiwan

Submission: November 20, 2020; Published: December 01, 2020

*Corresponding author: Guey-Lin Hou, Former Professor, Graduate Institute of Dental Science, Department of Periodontics, Kaohsiung Medical University, Taiwan

\section{Abstract}

Purpose: The purpose of the present study was retrospectively to investigate the association between the types of molar root trunk and molar loss with Class III furcation involvement (FI). A total of 169 extracted teeth from 164 patients, which consisted of 103 maxillary, 66 mandibular first and seconds, diagnosed of severely advanced periodontitis with Class III FI.

Materials and Methods: These molars were found affected alveolar bone loss more than 70\% using an ECM. The vertical dimension of root trunk was automatically categorized as A, B, and C root trunk type, where the assessment of CAL of extracted molars was calculated PRIA.

Result: The results demonstrated that a significant relationship existed; 1 ) between molar location, prevalence and distribution of extracted molars ( $\mathrm{p}<0.001) ; 2$ ) between RTT and molar location ( $\mathrm{p}<0.001)$, furcation sites $(\mathrm{p}<0.05)$, as well as 3 ) between RTT and PAL ( $<<0.05)$.

Conclusions: It was concluded that a close relationship does exist among molar teeth with long root trunk and loss of molars affected with class III FIs.

Keywords: Molar root trunkl Molar loss; Class III Furcation defect

Abbreviation: FI: Furcation Involvement; BRT: Buccal Root Trunk; MRT: Mesial Root Trunk; DRT: Distal Root Trunk; LRT: lingual root trunk; RRT: Root Trunk Type; FED: Furcation Entrance Dimension

\section{Introduction}

The diagnosis, prognosis, and treatment plan of molars with furcation involvement (FI) is one of the most challenging problems in periodontitis, due in part to the complexity in the dimension of furcation entrance, root divergent angle and degree of root separation, and molar root fusion [1-6]. Numerous studies have documented that molar root morphology may be a factor influencing the development of localized periodontal problems by providing an environment favorable to plaque retention [5,7-12]. Some investigators have suggested that a better understanding of molar root morphology, such as molar types, dimension of root trunk, [13-16], and characteristics of root cones [10,11,15] would be of help in the diagnosis, prognosis, and treatment plan of molar with FI. Based on an earlier study on type, dimension, distribution, root trunks and their respective root length, the benefit of using these root trunk types together with a classification of molar FI including assessment and correlating the relationship to varying degrees of root trunk with horizontal and vertical attachment loss had been reported [15].

Data on types and dimensions root trunks and their periodontal attachment level can be used as an aid in diagnosing Class III FI and the respective PALs. Our earlier report also showed that knowing the dimensions of buccal root trunk (BRT), mesial root trunk (MRT), and distal root trunk (DRT) of maxillary molars as well as the BRT, and lingual root trunk (LRT) of mandibular molars may be useful in assessing a more complete and thorough diagnosis of FI $[15,16]$. Several investigators [6,8,17] have reported that furcation sites responded less favorably to plaque control and root debridement than molar flat surfaces and nonmolar sites. Other clinicians also have addressed that the anatomy of roots at furcation sites may influence professional and personal 
plaque control and plaque deposition with further deterioration of periodontal attachment [1,2,8]. Most of investigators have been interested in the response of furcation areas to surgical and/or non-surgical periodontal therapy [18-20]. Recent reports reemphasized that failure of periodontal therapy to avoid further destruction of periodontal furcation-involved lesions appeared to be strongly associated with morphological problems and limited furcation entrance access, which may interfere with the efficacy of both personal as well as professional plaque control $[10,15,16,18,19,21]$.

Recently, we have retrospectively evaluated extracted molars, which were randomly collected from local dental clinics, addressing the relationship between root trunk type (RTT) and dimension of root trunk and diagnosis of molar FI [15]. We concluded that root trunk type together with horizontal and vertical attachment levels may be helpful for the diagnosis of molar FI. Molars with long root trunk do not easily develop FI when compared to molars with short root trunk. Periodontal problems such as severe attachment loss with a resultant molar loss may occur when molars with long root trunk develop Class III FI $[10,15]$. In addition, if root trunk is long, FI occurs later but once established, the amount of periodontal tissue support apical to the furcation may be difficult to all root separation and resection. Little or no data is available correlating RTT and furcation entrance dimension (FED) with loss of molar with FI. The present study was designed to evaluate retrospectively the possible relationship between different types of root trunk and extracted molars with Class III FI lost following, prior to, or during periodontal therapy.

\section{Materials and Methods}

\section{Criteria for molar extraction}

A total of 169 molars with Class III furcation defects in 164 patients were treated from 1982 to 1997 in an intramural practice at The Kaohsiung Medical College, Department of Periodontics. The subjects included both males and females between 24 to 84 years, with a mean age of $47.8 \pm 7.2$. Proper informed consent was obtained from each patient. Among 441 molars with Class III FI, 174 molars lost (103 maxillary and 71 mandibular) extracted prior to, during, or after treatment were designed as the test group (Table 1 \& 2), the remaining 267 molars retain (121 maxillary and 146 mandibular) affected by Class III FI were assigned as the Control group. Molars were extracted according to these criteria: 1) Molars originally having advanced periodontitis with radiographic bone loss of more than 75\% and Class III FI, [7] treated by surgical and/ or non-surgical periodontal therapy followed by maintained on 1-3-month recall for supportive treatment of maintain phase prior to June 1997; 2) Molars being diagnosed extracted as hopeless at initial evaluation. Other criteria for extraction were radiographic, clinical probing, pulp examination, age, gender, number of teeth present, initial degree of FI, modalities of periodontal therapy, and reasons for molar extraction. Molars were considered lost due to advanced bony destruction involving class III FI if it was extracted when molar consistently compromised the mastication, occlusal function and health of the patient. A final diagnosis and prognosis evaluation of molar was made to determine the initial and final periodontal prognosis and defined as questionable [22] (longterm) and hopeless [23] (short term) prognosis after treatment of phases I, II, III, and IV. Molar with pulpal pathology were not included in the study. The molars collected were not restored with crowns or bridges, or damaged, which could prevent the extract assessment of vertical dimension of the root trunk and root length. The extracted molars were washed in tap water, recorded, and kept in formalin solution after removing hard root deposits with mechanical and ultrasonic scaling (Figure 1).

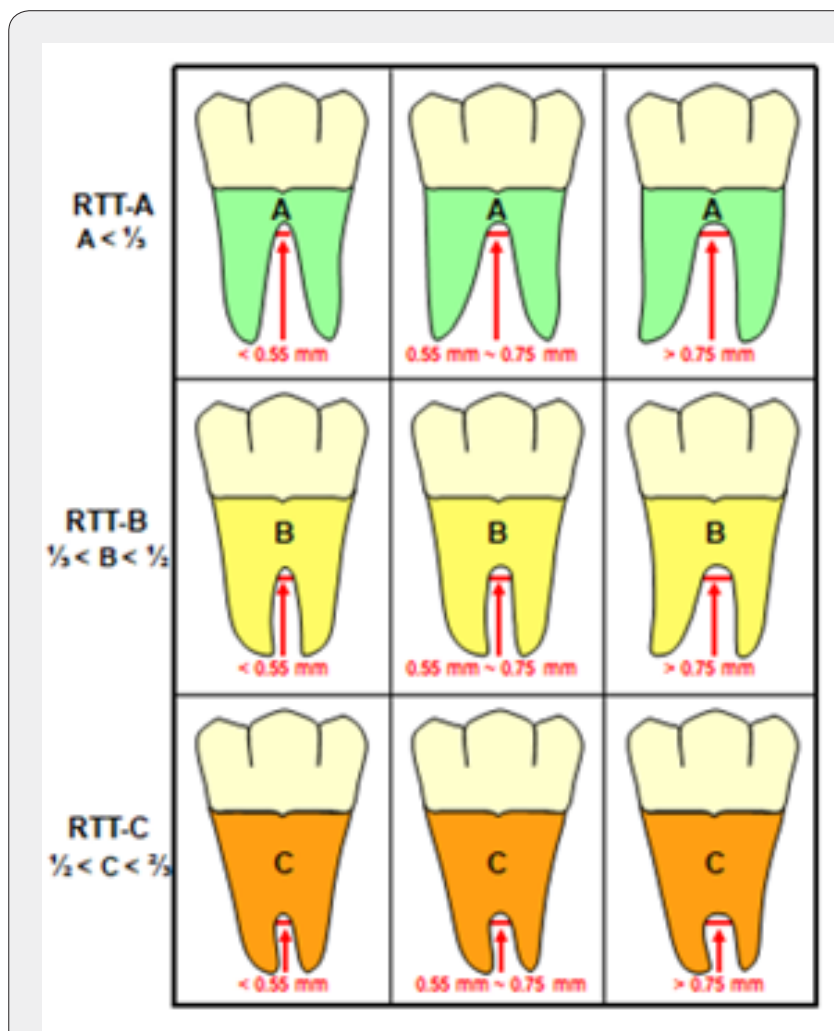

Figure 1: Hou's Classification of molar furcation involvement [16].

\section{Measurement of the vertical dimension of molar root trunk}

Vertical dimensions of the root trunks and root length were measured using an Electric Caliper Micrometer (ECM) (NSK, MaxCaliper, Japan Micro- meter, MFG Co. Ltd.) and then their means and standard deviations were calculated. Measurements including the vertical height of the BRT, the MRT, and the DRT of maxillary molars, as well as the BRT, and the LRT of the mandibular molars were performed. Root trunk was classified according to the ratio of root trunk height to root length as type $\mathrm{A}, \mathrm{B}$, and $\mathrm{C}$, as reported previously [15]. Types A, B, and C root trunks are defined as those involving cervical third or less, cervical third to one half and cervical two-thirds or greater, of the root length, respectively 
$[15,16]$. The grading method of root trunk was automatically categorized by the ratio of the vertical dimension of molar root trunk to the root length using the computer equipped with an automatic grading system (AGS)* as described earlier [24]. (*: Designed by our research group) (Figure 2).

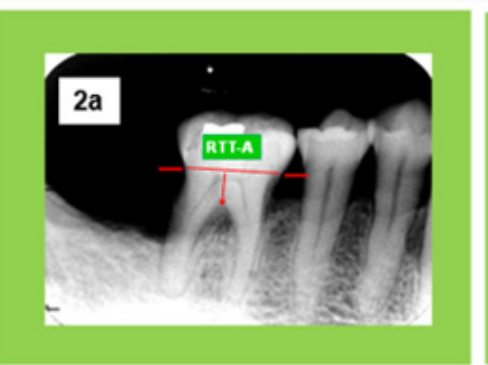

2(a) Root trunk Type A

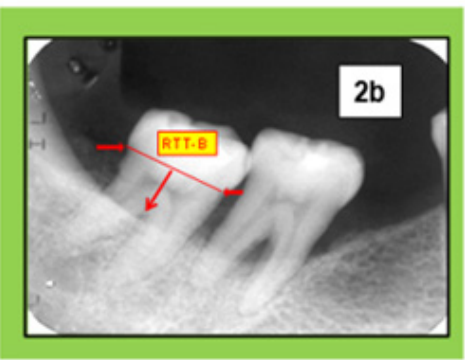

2(b) Root trunk Type B

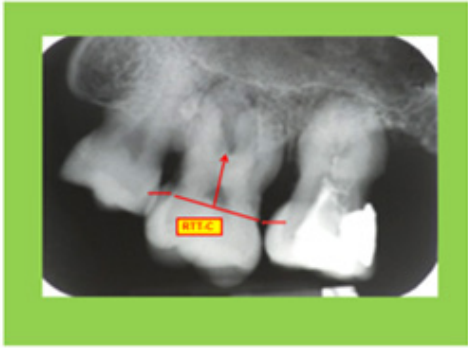

2(c) Root trunk Type C

Figure 2: Show molar root trunk type based on the periapical radiographic images.

Table 1: Shows that the difference of distribution and prevalence of RTT on maxillary first ( 45 \& 87 teeth) and second (58 \& 34 teeth) molars with Class III FI between the test group and the control group.

\begin{tabular}{|c|c|c|c|c|c|c|}
\hline \multirow{2}{*}{ Molar Type } & Test/Control Group & Molars with Class III FI & RTT-A A n (\%) & RTT-B B n (\%) & RTT-C C n (\%) & Significance \\
\hline \multirow{2}{*}{$16 \& 26$} & Test group & 45 & $7(5.3)$ & $25(18.9)$ & $13(9.9)$ & $\mathrm{t}=20.181$ \\
\cline { 2 - 7 } & Cont. group & 87 & $41(31.1)$ & $39(29.6)$ & $7(5.3)$ & $\mathrm{P}<0.0001$ \\
\hline \multirow{2}{*}{ Total } & 132 & 132 & $48(36.4)$ & $64(48.5)$ & $20(15.1)$ & $S^{* * * *}$ \\
\hline \multirow{2}{*}{$17 \& 27$} & Test group & 58 & $4(4.4)$ & $16(17.4)$ & $38(41.3)$ & $\mathrm{t}=42.774$ \\
\cline { 2 - 8 } & Cont. group & 34 & $12(13.0)$ & $18(19.6)$ & $4(4.4)$ & $\mathrm{p}>0.0001$ \\
\hline Total & 92 & 92 & $16(17.4)$ & $34(37.0)$ & $42(45.6)$ & $S^{* * * *}$ \\
\hline
\end{tabular}

Table 2: Indicates the difference of distribution and prevalence of RTT on mandibular first (13 \& 99 teeth) and second (58 \& 47 teeth) molars with Class III FI between the test group and the control group.

\begin{tabular}{|c|c|c|c|c|c|c|}
\hline \multirow{2}{*}{ Molar Type } & Test/Control Group & Molars with Class III FI & RTT-A n (\%) & RTT-B n (\%) & RTT-C n (\%) & Significance \\
\hline \multirow{2}{*}{$36 \& 46$} & Test group & 13 & $10(8.9)$ & $2(1.8)$ & $1(0.9)$ & $t=0.711$ \\
\cline { 2 - 7 } & Cont. group & 99 & $63(56.3)$ & $35(31.2)$ & $1(0.9)$ & P $>0.05$ \\
\hline \multirow{2}{*}{ Total } & 112 & 112 & $73(65.2)$ & $37(33.0)$ & $2(1.8)$ & NS \\
\hline \multirow{2}{*}{$37 \& 47$} & Test group & 58 & $6(5.7)$ & $18(17.1)$ & $34(32.4)$ & $t=94.735$ \\
\cline { 2 - 7 } & Cont. group & 47 & $28(26.7)$ & $17(16.2)$ & $2(1.9)$ & $\mathrm{p}>0.0001$ \\
\hline Total & 105 & 105 & $34(32.4)$ & $35(33.3)$ & $36(34.3)$ & $S^{* * * *}$ \\
\hline
\end{tabular}




\section{The Measurements of PAL}

Clinical records included patient's age, gender, and degree of molar FI. PALs for intra-furcation of maxillary molar roots as well as buccal and lingual intra-furcations of mandibular molar roots, were determined after tooth extraction using methylene blue staining. Clinical probing and routine periapical radiographic examinations were taken on molars to ensure the degree of FI. The PAL of 441 molars furcation sites (169 isolated molars) with class III FI accounting for more than $75 \%$ of all sites was assessed by a stereomicroscope equipped with micrometer scale.

\section{Statistical analysis}

The mean and standard deviation of root trunk length, root length, and PAL was calculated by SAS/JMP. (SAS Institute Inc., Cary, NC, USA; JMP Version 3.2) The relationship between RTTs and molar locations, and furcation sites among maxillary and mandibular molars was analyzed by Chi-square test. Mean value and standard deviations between types of molar root trunks among maxillary and mandibular molars were also calculated. Differences between the RTT with respect to molar types, furcation sites, and PAL was analyzed by one-way ANOVA.

\section{Results}

Table 1 shows that the difference of distribution and prevalence of RTT on maxillary first ( $45 \& 87$ teeth) and second (58 \& 34 teeth) molars with Class III FI between the test group and the control group. Result indicated that the prevalence of loss of maxillary first molars with Class III FI was found greater on both $18.9 \%$ with RTT-B (25/132 teeth loss) and 9.9\% with RTT-C (13/ 132 teeth loss) than those on $5.3 \%$ (7/132) of loss of molars with RTT- A ( 7/132 teeth). In addition, the prevalence of loss of maxillary second molars with Class III FI was found greater on both $41.3 \%$ with RTT-C (41/92 teeth loss) and 9.9\% with RTT-B
(16/92 teeth loss) than those of 4.4\% (4/92 teeth loss) of molars with RTT- A. It can be concluded that the higher prevalence of loss of molar affected Class III FI with long root trunk than those molar with short root trunk, especially occurred on the maxillary second molar ( RTT-C $=41.3 \%$; 38/92) as compared to the first molar (RTT-C $=9.9 \%$; 13/122). A significant relationship between molar RTT and extraction the number of molars extracted in both of maxillary first $(\mathrm{X} 2=20.22, \mathrm{p}<0.0001)$ and second molars $(\mathrm{X} 2=$ 42.77, $\mathrm{p}<0.0001)$.

Table 2 indicates the difference of distribution and prevalence of RTT on mandibular first (13 \& 99 teeth) and second (58 \& 47 teeth) molars with Class III FI between the test group and the control group. Result indicated that the prevalence of loss of mandibular first molars with Class III FI was found greater on both $8.9 \%$ with RTT-A (10/112 teeth loss) than those on $1.8 \%$ (2/112) of loss of molars with RTT- B ( 7/132 teeth). In addition, the prevalence of loss of mandibular second molars with Class III FI was found greater on $32.4 \%$ with RTT-C $(34 / 105$ teeth loss) and $17.1 \%$ with RTT-B (18/105 teeth loss) than those of $5.7 \%(6 / 105$ teeth loss) of molars with RTT- A. A non-significant relationship between molar RTT and extraction the number of molars extracted in both of mandibular first (X2 $=0.711, \mathrm{p}>0.05)$, but the significant relationship between molar RTT and extraction the number of molars extracted in second molars (X2 $=94.735$, $\mathrm{p}<0.0001$ ). It can be concluded that the higher prevalence of loss rate of molar affected Class III FI with long root trunk (RTT-C) was only occur on the mandibular second molars.

\section{Maxillary first and second molars}

Table 3 indicated that the prevalence of buccal furcation of loss of maxillary first molars (16 \& 26) with Class III FI was found greater on $24.3 \%$ with RTT-B (25/45 teeth loss) and least on RTT-C $(7 / 45 ; 6.8 \%)$.

Table 3: Demonstrated the relationships between RTT and furcation sites on 174 extracted maxillary and mandibular first and second molars in 169 individuals affected periodontitis.

\begin{tabular}{|c|c|c|c|c|c|}
\hline Furcation Sites (103) & RTT & $16 \& 26(45)$ n (\%) & $17 \& 27(58)$ n (\%) & t-value & Chi-Square Test \\
\hline $\begin{array}{c}\text { Buccal } \\
\text { Furcation }\end{array}$ & $\begin{array}{l}\mathrm{A} \\
\mathrm{B} \\
\mathrm{C}\end{array}$ & $\begin{array}{c}13(12.6) \\
25(24.3) \\
7(6.8)\end{array}$ & $\begin{array}{c}6(5.8) \\
26(25.2) \\
26(25.2)\end{array}$ & 12.657 & $\mathrm{P}<0.005$ \\
\hline Mesial Furcation & $\begin{array}{l}\text { A } \\
\text { B } \\
\text { C }\end{array}$ & $\begin{array}{c}5(4.9) \\
25(24.3) \\
15(14.6)\end{array}$ & $\begin{array}{c}3(2.9) \\
12(11.7)\end{array}$ & 17.625 & $\mathrm{P}<0.001$ \\
\hline Distal Furcation & $\begin{array}{l}\text { A } \\
\text { B } \\
\text { C }\end{array}$ & $\begin{array}{c}6(5.8) \\
24(23.3) \\
15(14.6)\end{array}$ & $\begin{array}{c}3(2.9) \\
21(20.4) \\
34(33.0)\end{array}$ & 7.13 & $\mathrm{P}<0.05$ \\
\hline $\begin{array}{l}\text { Furcation } \\
\text { Sites (71) }\end{array}$ & RTT & $\begin{array}{c}36 \& 46(13) \\
n(\%)\end{array}$ & $\begin{array}{c}37 \& 47(58) \\
n(\%)\end{array}$ & t-value & $\begin{array}{c}\text { Chi-square } \\
\text { test }\end{array}$ \\
\hline Buccal Furcation & $\begin{array}{l}\mathrm{A} \\
\mathrm{B} \\
\mathrm{C}\end{array}$ & $\begin{array}{c}10(14.1) \\
2(2.8) \\
1(1.4) \\
\end{array}$ & $\begin{array}{c}6(8.5) \\
20(28.2) \\
32(45.1)\end{array}$ & 22.293 & $\mathrm{P}<0.0001$ \\
\hline Lingual Furcation & $\begin{array}{l}\text { A } \\
\text { B } \\
\text { C }\end{array}$ & $\begin{array}{l}7(9.9) \\
5(7.0) \\
1(1.4)\end{array}$ & $\begin{array}{c}6(8.5) \\
18(25.4) \\
34(47.9)\end{array}$ & 17.198 & $\mathrm{P}<0.0001$ \\
\hline
\end{tabular}


i. Buccal Furcation: The prevalence of buccal furcation loss of maxillary second molars (17 \& 27) with Class III FI was found greater on RTT-B, RTT-C with 26 (25.2\%) and 26 (25.2\%). It is a significant relationship between molar RTT and extraction the number of molars extracted in both buccal furcation of maxillary first and second molars (X2 = 12.657, $\mathrm{p}<0.005)$ using Chi-square test.

ii. Mesial Furcation: The prevalence of RTT-B on the mesial furcation was found on the maxillary first molars and gave a $24.5 \%$ (25/103); where there were a significant relationship between maxillary first and second molars $(X 2=17.625, p<0.001)$.

iii. Distal Furcation: The higher prevalence of RTT-B on the distal furcation was found on the maxillary first molars and gave a $23.3 \%$ (24/103). In addition, the greatest prevalence of RTT-C was found on the maxillary secondary molar as compared to buccal and mesial furcations of both first and second molars. It revealed a weak significant between the maxillary first and second molars using Chi-quare test $(\mathrm{t}=7.13, \mathrm{p}<0.05)$.

\section{Mandibuar first and second molars}

Table 3 also showed that the prevalence of buccal furcation of loss of mandibular first molars ( $36 \& 46$ ) with Class III FI was found greater on $14.1 \%$ with RTT-A (10/71 teeth loss) and RTT-C(1.4\%) is the least (1/71).

a) Buccal Furcation: In addition, the greatest prevalence was located on the buccal furcation of loss of mandibular second molars, and gave a highest incidence of 45.1\% (32/71)and 28.2\% (20/71) on both of RTT-C and RTT-B, respectively.

b) Lingual Furcation: The highest prevalence of RTT-C was located at the lingual furcation mandibular second molars and gave an incidence of $47.9 \%$ (LF: $34 / 71$ ). The second incidence was the RTT-B with an incidence of $25.4 \%$ (LF: 18/71). Results showed that the longest root trunk (RTT-C) was the highest incidence on the buccal and lingual furcations of mandibular second molars; second incidence was the distal furcation 33.0\% (DF 34/103) of maxillary second molars; the least incidence was located on the buccal (1.4\%: BF; $1 / 71)$ and lingual (1.4\%: LF; $1 / 71)$ furcations of maxillary first molars, respectively (Table 3 ).

\section{Discussion}

Little of limited information is available regarding a relationship between RTT and molar furcation. The present results also showed that the majority of extracted molar furcation were affected with RTT- C and RTT-B root trunk in both second maxillary $(33.0 \% \mathrm{DF}$ and $25.2 \% \mathrm{BF}$ ) and second mandibular ( $46.2 \%$ RTT-C and 25.0\%) molars when compared to RTT-A (3.9\% and 9.1\%). A strong significant relationship (X2=93.67, $\mathrm{p}<0.001)$ between molar root trunk and molar location suggests that the majority of the extracted molars examined had a relatively higher prevalence in the RTT-C $(33.3 \%$ and $46.2 \%)$ and RTT-B ( $19.2 \%$ and $25 \%$ ) root trunk than the RTT-A ( $3.9 \%$ and $9.1 \%$ ) in the second maxillary and mandibular molars. In addition, the prevalence of RTT-C affected more frequently in the second molar $(33.3 \%$ and $46.2 \%)$ as compared the first $12.0 \%$ and $0.8 \%$ ). little or limited data, about the relationship between the molar type and classification of molar RTT for the individuals with severely advanced periodontitis, is available. The interesting finding of the present study provides a strong evidence to support the speculation of a former study [15] suggesting that advanced furcation-involved molars extracted with RTT-C affected second molars more frequently than fist molar.

Limited information is available regarding the prevalence of the RTT-A, RTT-B, and RTT-C affecting the furcation sites at the buccal, mesial, distal and lingual furcatuons. Statistical analysis suggests a significant relationship between types of molar root trunk and associated furcation sites $\left(\mathrm{X}^{2}=14.25\right.$; $\mathrm{df}=6$; $\left.\mathrm{p}=0.027\right)$. The present study showed that the majority of the extracted hopeless molars with RTT-C were more commonly observed buccally (33.8\%) and mesially (28.4\%) than distally (23.9\%) and lingually (13.9\%). Recently, a detailed morphologi- cal description was addressed which provided a grading system of molar root trunks based on the extracted molars collected from adult individuals treated in local dental clinics $[15,16]$. The conclusion showed that RTT-A was more commonly found on buccal (53.0\%) than on distal (15.2\%), lingual (19.7\%) and mesial (12.1\%) furcations.

In the present study, an interesting finding is that there exists a relatively higher prevalence ( maxillary and mandibular second molars accounted for $33.3 \%$ and $46.2 \%$ ) of Class III furcationinvolved molars affected with RTT-C amongst the extracted molars collected from the periodontal department in the teaching hospital. In contrast, a lower prevalence of RTT-C affected molars losses (18.4\% and $9.3 \%$, respectively) which were randomly collected from the local dental clinics [16]. This information possibly suggests that a long root trunk probably has a higher potential risk for teeth loss than a short root trunk in molars affected with Class III FI. In addition, the difference of molar extraction criteria between the periodontist and dentist at local dental clinic cannot be excluded [25]. It is concluded that there probably exists a closer relationship between molar root trunk and loss of molars in teeth affected with Class III furcation and severe alveolar bone loss. This study provides evidence to support previous hypothesis that molars with long root trunk do not easily develop furcation involvement when compared to molars with short root trunk. However, periodontal problems such as severe attachment loss with a resultant molar loss may occur when molars with TTT-B or RTT-C develop Class III molar FI [10,15].

\section{References}

1. Bower RC (1979a) Furcation morphology relative to periodontal treatment. Furcation entrance architecture. J Periodontol 50(1): 23-27.

2. Bower RC (1979a) Furcation morphology relative to oeriodontal treatment. Furcation root surface anatomy. J Periodontol 50(7): 366374. 
3. Eskow RN, Kaspin SH (1984) Furcation invasions: Correlating a classification system with therapeutic considerations. Part. Examination, diagnosis, and consideration. Comp Contin Edu Dent 5(7): 527-532.

4. Tarnow OP, Fletcher P (1984) Classification of the vertical component of furcation involvement. J Periodontol 55(5): 283-284.

5. Hou GL, Tsai CC (1987) Relationship periodontal furcation involvement and molar cervical enamel projection. J Periodontol 58(10): 715-721.

6. Hou GL, Chen SF, Wu YM, Tsai CC (1994) Topography of the furcation entrance in Chinese molars. Furcation entrance dimension. J Clin Periodontol 21(7): 451-456.

7. Hamp SE, Nyman S, Lindhe J (1975) Periodontal treatment of multirooted molar. Results after 5 years. J Clin Periodontol 2(3): 126135

8. Waerhoug J (1980) The furcation problem: Etiology, pathogenesis, diagnosis, therapy and prognosis. J Clin Periodontol 7(2): 73-95.

9. Svardstrom G, Wennstrom JL (1988) Furcation topography of the maxillary and mandibular molars. J Clin Periodontol 15(5): 271-275.

10. Carvenale G, Pontoriero R, Lindhe J (1997) Treatment of furcationinvolved teeth. In: Lindhe J, Karring T, Lang N, Munkagaard(Eds.), Clinical Periodontology and Implant Dentistry. ( $3^{\text {rd }}$ edn), Copenhagen pp. 682-710.

11. Hou GL, Tsai CC (1997a) Relationship between molar root fusion and localized periodontitis. J Periodontol 68(4): 313-319.

12. Hou GL, Tsai CC (1997b) Cervical enamel projection and intermediate bifucational ridge correlated with molar furcation involvements. J Periodontol 68(7): 687-693.

13. Lalato DC (1975) Some anatomical factors related to furcation involvements. J Periodontol 46(10): 608-609.

14. Gher MW, Vermino AR (1980) Root morphology - Clinical significance in pathogenesis and treatment of periodontal disease. J Amer Dent Assoc 101(4): 627-633.
15. Hou GL, Tsai CC (1997c) Types and dimensional of root trunk correlating with diagnosis of molar furcation involvements. J Clin Periodontol 24(2): 129-135.

16. Hou GL, Cheng YM, Tsai CC, Weisgold AS (1998) A new classification of molar furcation involvement based on the root trunk and horizontal and vertical bone loss. Int J Periodon Res Dent 18(3): 257-265.

17. Nordland P, Garrett S, Kigger R, Vanooteghem R, Hutchens LH, et al. (1987) The effect of plaque control and root debridement in molar teeth. J Clin Periodontol 14(4): 231-236.

18. Kalkwarf KL, Kaidahl WD, Patil KD (1988) Evaluation of furcation region response to periodontal therapy. J Periodontol 59(12): 794-804.

19. Kaldahl WB, Kalkwarf KL, Patil KD, Dyer JK, Bates RE (1988) Evaluation of four modalities of periodontal therapy. J Periodontol 59(12): 783793.

20. Pontoriero R, Lindhe J (1995) Guided tissue regeneration in the treatment of degree-III furcation defects in maxillary molars. J Clin Periodontol 22(10): 810-812.

21. Otero-Cagide FJ, Long BA (1997) Comparative in vitro effectiveness of closed root debridement with fine instruments on specific areas of mandibular first molar furcations. I. Root trunl and furcation entrance. J periodontal 68(11): 1093-1097.

22. Hirschfeld L, Wasserman B (1998) A long term survey of tooth loss in 600 treated periodontal patients. J Periodontol 49(5): 225-237.

23. Becker W, Berg L, Becker BE (1984) The long-term evaluation of periodontal treatment and maintenance in 95 patients. In J Periodont Res Dent 4(2): 55-71.

24. Hou GL, Shieh TY, Tsai CC, Yang YH, Huang JS (1998) Relationship between root trunk type and periodontal attachment loss in molars. J Dent Res 77: 993.

25. Klock KS, Haugejorden Ola (1993) In vivo determination of the forceps level for extraction of teeth for periodontal reasons. J Clin Periodontol 20(3): 155-160

Your next submission with Juniper Publishers
will reach you the below assets
- Quality Editorial service
- Swift Peer Review
- Reprints availability
- E-prints Service
- Manuscript Podcast for convenient understanding
- Global attainment for your research
- Manuscript accessibility in different formats
( Pdf, E-pub, Full Text, Audio)
- Unceasing customer service
Track the below URL for one-step submission
https://juniperpublishers.com/online-submission.php

